\title{
RESEARCH BRIEF \\ Relationship Between Adherence to Antihypertensive Medication Regimen and Out- of-Pocket Costs Among People Aged 35 to 64 With Employer-Sponsored Health Insurance
}

\author{
Madeleine M. Baker-Goering, $\mathrm{PhD}^{1}$; Kakoli Roy, $\mathrm{PhD}^{1}$; David H. Howard, $\mathrm{PhD}^{2}$
}

\begin{abstract}
Accessible Version: www.cdc.gov/pcd/issues/2019/18_0381.htm
Suggested citation for this article: Baker-Goering MM, Roy K, Howard DH. Relationship Between Adherence to Antihypertensive Medication Regimen and Out-of-Pocket Costs Among People Aged 35 to 64 With Employer-Sponsored Health Insurance. Prev Chronic Dis 2019;16:180381. DOI: https:// doi.org/10.5888/pcd16.180381.
\end{abstract}

\section{PEER REVIEWED}

\section{Summary}

What is already known about this topic?

Only $40 \%$ to $74 \%$ of patients treated for hypertension take medications as prescribed. Patients' out-of-pocket costs for medications can affect medication adherence.

What is added by this report?

We found a substantial proportion of people aged 35 to 64 with employersponsored health insurance to be nonadherent to antihypertensive medications (41\%). People paid an average $\$ 6$ for a 30-day supply of medication in 2014, and those paying higher out-of-pocket costs had a greater likelihood of being nonadherent.

What are the implications for public health practice?

The results highlight room for improvement in medication adherence among patients with employer-sponsored health insurance, even if facing small out of pocket costs.

\section{Abstract}

We used administrative claims data from 2014 on people with employer-sponsored health insurance to assess the proportion of patients taking antihypertensive medications, rates of nonadherence to these medication regimens, and out-of-pocket costs paid by patients. We performed multivariate logistic regression analysis to examine the association between out-of-pocket costs and nonadherence. Results indicated that patients filled the equivalent of 13 monthly prescriptions and paid $\$ 76$ out of pocket over the calendar year; the likelihood of nonadherence increased as out-of-pocket costs increased (adjusted odds ratios ranged from 1.04 to 1.78; $P$ $<.001)$. These findings suggest a need for improvement in adherence among patients with employer-sponsored insurance.

\section{Objective}

Hypertension is a leading risk factor for cardiovascular disease, and only $40 \%$ to $74 \%$ of people with diagnosed hypertension are adherent to prescribed medication (1-3). Nonadherence can result in uncontrolled hypertension, which increases the risk of acute cardiovascular disease events $(4,5)$. People who take many different drugs, experience side effects from hypertension medication, have comorbidities, or face high out-of-pocket costs are more likely to be nonadherent (6). No recent studies among the privately insured population of the United States describe rates of nonadherence and actual out-of-pocket payments for antihypertensive medications.

\section{Methods}

We used 2014 administrative claims data from the IBM MarketScan Commercial Database (IBM Corp), which provided de-identified health care claims data for enrollees and their dependents in employer-sponsored health insurance plans. We limited the study sample to adults aged 35 to 64 who were continuously enrolled with prescription drug coverage in $2014(\mathrm{~N}=3,362,633)$. We focused on 2014 after using the IBM Treatment Pathways online tool (IBM Corp), which reported stable trends of proportions of patients with any hypertension diagnosis $(25 \%-26 \%)$ and proportions of patients filling an antihypertensive medication prescription $(29 \%-30 \%)$ in 2010 through 2014.

We identified people with hypertension by the appearance of International Classification of Diseases, 9th Revision (ICD-9), dia- 
gnosis codes (401.x-405.x) on at least 2 outpatient or 1 inpatient or emergency department claim, and we identified cardiovascular disease events resulting in an inpatient or emergency department visit by using ICD-9 codes from the Center for Medicare and Medicaid Services' Chronic Conditions Warehouse for ischemic heart disease, acute myocardial infarction, cerebrovascular disease, and heart failure (398.91, 402.x-404.x, 410.x, 411.x-413.x, 414.0x, 414.12, 414.2, 414.3, 414.8, 414.9, 428.x, 430.x, 431.x, 433.x1, 434.x, 436.x, 997.02) (7). We measured adherence to antihypertensive medications among enrollees with at least 1 antihypertensive drug claim in 2014. We identified antihypertensive medications by Redbook drug codes for therapeutic class (except for angiotensin II receptor blockers, which we identified by using National Drug Codes, because they were not identified in Redbook by therapeutic class) (8). We measured the proportion of days covered (days covered equaled the patient's supply of medication from the day of the first filled prescription through the end of the calendar year), divided by the number of days in that same period, calculated for each medication class, and then averaged across number of medication classes per person. Enrollees with less than $80 \%$ of days covered were considered nonadherent, a cutoff used in many studies $(4,9)$. We report total out-of-pocket cost (sum of copayments, coinsurance, or deductibles) and total payments for antihypertensive medications. We also reported number of filled prescriptions and out-of-pocket and total medication costs for a 30-day equivalent supply of antihypertensive medications (eg, 15 days of supply becomes 0.5 of a 30-day fill). Outof-pocket costs was converted to a categorical variable $(\$ 0,<\$ 5$, $\$ 5-<\$ 10, \$ 10-<\$ 15, \$ 15-<\$ 20, \$ 20-<\$ 50$, and $\geq \$ 50)$.

We used multivariate logistic regression to estimate the association between category of out-of-pocket cost and the likelihood of being nonadherent and presented these data as odds ratios. We used Stata 12 SE (StataCorp, LLC) to analyze data.

\section{Results}

In 2014, $22 \%$ of adults aged 35 to $64(\mathrm{~N}=2,897,548)$ were diagnosed with hypertension (Table 1). Among the $27 \%(\mathrm{~N}=$ $3,462,582)$ of adults who filled prescriptions for antihypertensive medications, $41 \%(\mathrm{~N}=1,428,298)$ of those who filled a prescription were nonadherent to their antihypertensive medication regimen. Nonadherence decreased with age and was higher for women than men and for people using branded medications than those using generic ones. Regionally, nonadherence was highest among people living in the South.

Patients filled an average of 13 monthly antihypertensive medication prescriptions during the calendar year and paid on average $\$ 5.78$ out of pocket per 30 -day supply and $\$ 76$ annually. Total costs (patient and insurer) for antihypertensive medications were $\$ 17$ per 30-day supply and \$229 annually. People who used branded medications had the highest out-of-pocket costs $(\$ 13.60$ per 30-day supply) and highest total costs ( $\$ 40.73$ per 30-day supply). Patients in health maintenance organizations had higher outof-pocket costs that those in other types of insurance plans. Residents of rural areas also had higher out-of-pocket costs than those paid by those in urban areas, but they used less expensive medications.

About $90 \%$ of patients incurred out-of-pocket costs for medications, but $83 \%$ paid less than $\$ 10$ per 30 -day supply of antihypertensive medications. However, $30 \%$ of patients paid the full costs of their medications (approximately $\$ 41$ in annual out-of-pocket costs for an average of 10 fills during the calendar year.).

We calculated the unadjusted and multivariate-adjusted odds ratios for the association between nonadherence and patient characteristics (Table 2). The likelihood of nonadherence increased as out-of-pocket costs increased (odds ratios, compared with those with no out-of-pocket costs, ranged from 1.04 for those paying less than $\$ 5$, to 1.78 for those paying more than $\$ 50$ ).

The likelihood of nonadherence was greatest among patients who used branded antihypertensive medications and those living in the South and was smallest among those with a hypertension diagnosis in 2014 and patients aged 55 to 64 . When we restricted the sample to patients with a hypertension diagnosis as a sensitivity analysis, the associations were similar in magnitude and significance.

\section{Discussion}

We found that nonadherence to antihypertensive medication regimens was common and was most common among patients with higher out-of-pocket costs. A 2016 study estimated that patients with commercial insurance paid about $\$ 4.13$ in copayments per antihypertensive medication prescription filled in 2014, slightly lower than the out-of-pocket cost estimate reported in our study, which provides a more comprehensive estimate that includes copayments, coinsurance, and deductibles (10).

Numerous experimental and quasi-experimental studies have found a causal relationship between lowering patients' out-ofpocket costs and reducing medication nonadherence (11). Our study shows an association between out-of-pocket costs and nonadherence among enrollees in employer-sponsored insurance plans. However, nonadherence is influenced by many other factors unrelated to cost, such as number of pills to be taken (eg, 1 daily medication versus combination medications) or the burden of filling prescriptions (eg, increasing the number of doses per pre-

\footnotetext{
The opinions expressed by authors contributing to this journal do not necessarily reflect the opinions of the U.S. Department of Health and Human Services, the Public Health Service, the Centers for Disease Control and Prevention, or the authors' affiliated institutions.
} 
scription, delivering prescriptions by mail) $(6,10,12)$. The data we used were collected for administrative purposes and were not nationally representative. In addition, claims data have many documented limitations, including that prescriptions filled do not measure actual medication used.

Our study findings show that there is room for improving adherence to antihypertensive medications among patients with employer-sponsored insurance and that patients who faced higher out-ofpocket costs had a greater likelihood of being nonadherent.

\section{Acknowledgments}

The authors thank Dr Mark Strand and the 3 anonymous reviewers from Preventing Chronic Disease for their helpful comments. Our research was supported by the Centers for Disease Control and Prevention (CDC). We used proprietary data from IBM MarketScan Commercial Database and used a proprietary online tool, IBM Treatment Pathways. IBM Watson Health and MarketScan are trademarks of IBM Corporation in the United States and other countries. No copyrighted material, surveys, or instruments were used. The findings and conclusions in this report are those of the authors and do not necessarily represent the official position of CDC. The authors report no conflicts of interest.

\section{Author Information}

Corresponding Author: Madeleine M. Baker-Goering, PhD, Office of the Associate Director for Policy, Centers for Disease Control and Prevention, 1600 Clifton Rd NE, MS US12-1, Atlanta, GA 30329-4027. Telephone: 404-639-5039. Email: MBakerGoering@cdc.gov

Author Affiliations: ${ }^{1}$ Office of the Associate Director for Policy, Centers for Disease Control and Prevention, Atlanta, Georgia. ${ }^{2}$ Department of Health Policy and Management, Rollins School of Public Health, Emory University, Atlanta, Georgia.

\section{References}

1. Benjamin EJ, Blaha MJ, Chiuve SE, Cushman M, Das SR, Deo R, et al.; American Heart Association Statistics Committee and Stroke Statistics Subcommittee. Heart disease and stroke statistics - 2017 update: a report from the American Heart Association. Circulation 2017;135(10): e146-603. Errata in: Circulation 2017; 7;135(10):e146-e603 and Circulation 2017; 136(10):e196.
2. Ritchey M, Chang A, Powers C, Loustalot F, Schieb L, Ketcham M, et al. Vital signs: disparities in antihypertensive medication nonadherence among Medicare Part D beneficiaries - United States, 2014. MMWR Morb Mortal Wkly Rep 2016;65(36):967-76.

3. Briesacher BA, Andrade SE, Fouayzi H, Chan KA. Comparison of drug adherence rates among patients with seven different medical conditions. Pharmacotherapy 2008; 28(4):437-43.

4. Pittman DG, Tao Z, Chen W, Stettin GD. Antihypertensive medication adherence and subsequent healthcare utilization and costs. Am J Manag Care 2010;16(8):568-76.

5. Will JC, Zhang Z, Ritchey MD, Loustalot F. Medication adherence and incident preventable hospitalizations for hypertension. Am J Prev Med 2016;50(4):489-99.

6. Gellad WF, Grenard J, McGlynn EA. A review of barriers to medication adherence: a framework for driving policy options. Santa Monica (CA): RAND Corporation; 2009. 66 p.

7. Center for Medicare and Medicaid Services. CMS Chronic Conditions Data Warehouse. CCW condition algorithms. https://www.ccwdata.org/documents/10280/19139421/ccwchronic-condition-algorithms.pdf. Accessed July 9, 2018.

8. Chobanian AV, Bakris GL, Black HR, Cushman WC, Green LA, Izzo JL Jr, et al.; National High Blood Pressure Education Program Coordinating Committee. The seventh report of the Joint National Committee on Prevention, Detection, Evaluation, and Treatment of High Blood Pressure: the JNC 7 report. JAMA 2003;289(19):2560-72.

9. Choudhry NK, Shrank WH, Levin RL, Lee JL, Jan SA, Brookhart MA, et al. Measuring concurrent adherence to multiple related medications. Am J Manag Care 2009; 15(7):457-64.

10. Ritchey M, Tsipas S, Loustalot F, Wozniak G. Use of pharmacy sales data to assess changes in prescription- and payment-related factors that promote adherence to medications commonly used to treat hypertension, 2009 and 2014. PLoS One 2016;11(7):e0159366.

11. Njie GJ, Finnie RK, Acharya SD, Jacob V, Proia KK, Hopkins DP, et al.; Community Preventive Services Task Force. Reducing medication costs to prevent cardiovascular disease: a Community Guide systematic review. Prev Chronic Dis 2015; 12:E208.

12. Schroeder K, Fahey T, Ebrahim S. Interventions for improving adherence to treatment in patients with high blood pressure in ambulatory settings. Cochrane Database Syst Rev 2004; (2):CD004804. 


\section{Tables}

Table 1. Characteristics of Sample of Adults Aged 35 to $64(\mathrm{~N}=3,362,633$ ), Study of Relationship Between Nonadherence to Antihypertensive Medication (AHM) Regimen and Enrollment in an Employer-Sponsored Health Insurance Plan, United States, 2014

\begin{tabular}{|c|c|c|c|c|c|c|c|c|c|}
\hline \multirow[b]{2}{*}{ Variable } & \multirow[b]{2}{*}{ No. Enrollees } & \multirow{2}{*}{$\begin{array}{c}\text { Diagnosed With } \\
\text { Hypertension, } \\
\text { N (\%) }\end{array}$} & \multirow[b]{2}{*}{$\begin{array}{l}\text { Treated With } \\
\text { AHM, N (\%) }\end{array}$} & \multirow{2}{*}{$\begin{array}{c}\text { Nonadherent } \\
\text { Among Treated, } \\
\mathrm{N}(\%)\end{array}$} & \multirow{2}{*}{$\begin{array}{c}\text { Number of } \\
\text { AHM } \\
\text { Prescriptions } \\
\text { Filled }\end{array}$} & \multicolumn{2}{|c|}{$\begin{array}{l}\text { Out of Pocket Cost, } \\
\text { AHM, } \$\end{array}$} & \multicolumn{2}{|c|}{$\begin{array}{l}\text { Total Cost, } \\
\text { AHM, } \$ \text {, e' }\end{array}$} \\
\hline & & & & & & $\begin{array}{l}\text { 30-Day } \\
\text { Supply }\end{array}$ & $\begin{array}{l}\text { Annual } \\
\text { Supply }\end{array}$ & $\begin{array}{l}\text { 30- Day } \\
\text { Supply }\end{array}$ & $\begin{array}{l}\text { Annual } \\
\text { Supply }\end{array}$ \\
\hline Total & $13,035,703$ & $2,897,548(22)$ & $3,462,582(27)$ & $1,428,298(41)$ & 13.2 & 5.78 & 76.24 & 17.34 & 228.57 \\
\hline \multicolumn{10}{|l|}{ Age, $y$} \\
\hline $35-44$ & $4,067,167$ & $436,240(11)$ & $576964(14)$ & $3,187,186(52)$ & 10.1 & 5.93 & 59.67 & 17.02 & 171.15 \\
\hline $45-54$ & $4,759,074$ & $10,21,153(21)$ & $1,237,594(26)$ & $2,756,655$ (43) & 12.5 & 5.86 & 73.22 & 17.36 & 217.02 \\
\hline $55-64$ & $4,209,462$ & $1,440,155(34)$ & $1,648,024(39)$ & $2,409,621(36)$ & 14.8 & 5.70 & 84.30 & 17.40 & 257.35 \\
\hline \multicolumn{10}{|l|}{ Sex } \\
\hline Male & $6,073,363$ & $1,469,555(24)$ & $1,690,278(28)$ & $2,442,685(40)$ & 13.7 & 5.81 & 79.55 & 17.67 & 241.87 \\
\hline Female & $6,962,340$ & $1,427,993(21)$ & $1,772,304(25)$ & $2,448,195(43)$ & 12.7 & 5.75 & 73.08 & 16.99 & 215.89 \\
\hline \multicolumn{10}{|c|}{ Insurance plan $^{f}$} \\
\hline PPO & $7,438,985$ & $1,806,612(24)$ & $1,996,135(27)$ & $2,286,115$ (41) & 13.2 & 5.84 & 77.14 & 18.26 & 241.06 \\
\hline HMO & $1,342,925$ & $290,178(22)$ & $351,450(26)$ & $3,261,165$ (43) & 13.1 & 6.23 & 81.77 & 16.45 & 216.07 \\
\hline $\mathrm{CD} / \mathrm{HD}$ & $2,158,440$ & $445,098(21)$ & $519,476(24)$ & $3,159,601(42)$ & 12.8 & 5.42 & 69.40 & 15.35 & 196.63 \\
\hline Otherg & $1,240,828$ & $333465(27)$ & $372,064(30)$ & $3,243,771(41)$ & 13.5 & 5.94 & 80.44 & 16.54 & 223.83 \\
\hline \multicolumn{10}{|l|}{ Region $^{h}$} \\
\hline Northeast & $2,708,175$ & $503,112(19)$ & $665,342(25)$ & $3,047,219$ (38) & 13.7 & 5.13 & 70.18 & 17.02 & 232.63 \\
\hline Midwest & $2,685,343$ & $577697(22)$ & $708,806(26)$ & $3,025,079$ (38) & 13.6 & 5.14 & 70.04 & 14.57 & 198.38 \\
\hline South & $5,156,805$ & $1,378,328(27)$ & $1,533,458(30)$ & $2,604,672(44)$ & 12.9 & 6.40 & 82.32 & 19.13 & 246.10 \\
\hline West & $2,156,128$ & $345,237(16)$ & $454,118(21)$ & $3,196,654(41)$ & 12.9 & 5.23 & 67.36 & 15.68 & 202.14 \\
\hline \multicolumn{10}{|c|}{ Geographic area } \\
\hline Urban & $11,269,871$ & $2,441,266(22)$ & $2,810,705$ (25) & $1,807,038(41)$ & 13.2 & 5.66 & 74.41 & 17.33 & 228.05 \\
\hline Rural & $1,765,832$ & $456,282(26)$ & $551,928(31)$ & $3,141,037(42)$ & 13.3 & 6.00 & 79.94 & 16.87 & 224.55 \\
\hline \multicolumn{10}{|c|}{ Type of AHM used ${ }^{i}$} \\
\hline Generics only & $3,041,215$ & $1,855,141(61)$ & $3,041,215(100)$ & $1,216,486(40)$ & 12.8 & 4.41 & 56.45 & 10.72 & 137.23 \\
\hline $\begin{array}{l}\text { Ever use } \\
\text { branded }\end{array}$ & 421,367 & $290,743(69)$ & $421,367(100)$ & $223,325(53)$ & 16.1 & 13.60 & 219.03 & 40.73 & 655.75 \\
\hline
\end{tabular}

Abbreviations: $\mathrm{CD} / \mathrm{HD}$, consumer driven or high deductible health plan; HMO, health maintenance organization; HTN, hypertension; PPO, preferred provider organization.

a Data are from IBM's MarketScan Commercial Database.

${ }^{\mathrm{b}}$ Outliers (negative values and $\geq 99$ th percentile for annual AHM cost and total payment) and missing values excluded.

${ }^{\mathrm{c}}$ 30-day equivalent fills.

${ }^{\mathrm{d}}$ This includes copayments, coinsurance, and deductibles.

${ }^{\mathrm{e}}$ Total payments include all payments made, including insurer payments, copayments, coinsurance, deductibles, and coordination of benefits payments.

${ }^{f}$ Plan type was missing for $7 \%$ of the sample.

${ }^{g}$ Other includes comprehensive, exclusive provider organization, and point of sale plans.

${ }^{\mathrm{h}}$ Region was missing for $3 \%$ of the sample.

${ }^{\mathrm{i}}$ This splits AHM users into 2 mutually exclusive groups: those who only filled prescriptions for generic AHMs in 2014 (88\%) and those who ever filled a prescription for a branded AHM in 2014 (12\%).

The opinions expressed by authors contributing to this journal do not necessarily reflect the opinions of the U.S. Department of Health and Human Services, the Public Health Service, the Centers for Disease Control and Prevention, or the authors' affiliated institutions. 
Table 2. Odds of Nonadherence to an Antihypertensive Medication Regimen in Relation to Out-of-Pocket Costs, Adults Aged 35 to 64 Enrolled in an EmployerSponsored Health Insurance Plan, United States, 2014 ${ }^{\mathrm{a}}$

\begin{tabular}{|c|c|c|c|c|}
\hline Variables & Unadjusted Odds Ratio (95\% Cl) & $P$ Value & Adjusted Odds Ratio ${ }^{\mathrm{b}}(95 \% \mathrm{Cl})$ & $P$ Value \\
\hline \multicolumn{5}{|c|}{ Out-of-pocket cost, 30-day supply of antihypertensive medication, \$ } \\
\hline 0 & \multicolumn{4}{|r|}{1 [Reference] } \\
\hline$<5$ & $0.99(0.98-1.00)$ & .003 & $1.04(1.04-1.05)$ & $<.001$ \\
\hline $5-<10$ & $1.35(1.34-1.37)$ & $<.001$ & $1.36(1.35-1.37)$ & $<.001$ \\
\hline $10-<15$ & $1.60(1.58-1.61)$ & $<.001$ & $1.51(1.49-1.52)$ & $<.001$ \\
\hline $15-<20$ & $1.77(1.74-1.79)$ & $<.001$ & $1.50(1.48-1.52)$ & $<.001$ \\
\hline $20-<50$ & $1.89(1.87-1.92)$ & $<.001$ & $1.44(1.42-1.46)$ & $<.001$ \\
\hline$\geq 50$ & $2.45(2.39-2.52)$ & $<.001$ & $1.78(1.73-1.83)$ & $<.001$ \\
\hline \multicolumn{5}{|l|}{ Age, y } \\
\hline $35-44$ & \multicolumn{4}{|r|}{1 [Reference] } \\
\hline $45-54$ & $0.69(0.68-0.69)$ & $<.001$ & $0.69(0.68-0.69)$ & $<.001$ \\
\hline $55-64$ & $0.52(0.51-0.52)$ & $<.001$ & $0.51(0.51-0.51)$ & $<.001$ \\
\hline \multicolumn{5}{|l|}{ Sex } \\
\hline Male & \multicolumn{4}{|r|}{1 [Reference] } \\
\hline Female & $1.14(1.13-1.14)$ & $<.001$ & $1.14(1.14-1.15)$ & $<.001$ \\
\hline \multicolumn{5}{|c|}{ Hypertension diagnosis in 2014} \\
\hline No & \multicolumn{4}{|r|}{1 [Reference] } \\
\hline Yes & $0.89(0.89-0.90)$ & $<.001$ & $0.88(0.87-0.88)$ & $<.001$ \\
\hline \multicolumn{5}{|c|}{ Cardiovascular disease event in 2014} \\
\hline No & \multicolumn{4}{|r|}{1 [Reference] } \\
\hline Yes & $2.00(1.97-2.02)$ & $<.001$ & $2.12(2.09-2.15)$ & $<.001$ \\
\hline \multicolumn{5}{|l|}{ Type of AHM used ${ }^{c}$} \\
\hline Generic AHMs only & \multicolumn{4}{|r|}{1 [Reference] } \\
\hline Any use of branded AHMs & $1.72(1.71-1.73)$ & $<.001$ & $1.52(1.51-1.52)$ & $<.001$ \\
\hline \multicolumn{5}{|l|}{ Type of insurance plan } \\
\hline PPO & \multicolumn{4}{|r|}{1 [Reference] } \\
\hline HMO & $1.07(1.06-1.08)$ & $<.001$ & $1.07(1.06-1.08)$ & $<.001$ \\
\hline $\mathrm{CD} / \mathrm{HD}$ & $1.03(1.02-1.03)$ & $<.001$ & $1.05(1.04-1.06)$ & $<.001$ \\
\hline Other & $1.01(1.00-1.01)$ & .15 & $1.04(1.03-1.04)$ & $<.001$ \\
\hline \multicolumn{5}{|l|}{ Region } \\
\hline Northeast & \multicolumn{4}{|r|}{1 [Reference] } \\
\hline Midwest & $1.03(1.02-1.04)$ & $<.001$ & $1.02(1.02-1.03)$ & $<.001$ \\
\hline South & $1.31(1.30-1.31)$ & $<.001$ & $1.24(1.23-1.25)$ & $<.001$ \\
\hline
\end{tabular}

Abbreviations: $\mathrm{CD} / \mathrm{HD}$, consumer driven or high deductible health plan; $\mathrm{Cl}$, confidence interval; $\mathrm{HMO}$, health maintenance organization; PPO, preferred provider organization.

a Data are from IBM's MarketScan Commercial Database.

${ }^{\mathrm{b}}$ Adjusted for variables listed in the table.

${ }^{\mathrm{C}}$ This splits AHM users into 2 mutually exclusive groups: those who only filled prescriptions for generic AHMs in 2014 (88\%) and those who ever filled a prescription for a branded AHM in 2014 (12\%). 
(continued)

Table 2. Odds of Nonadherence to an Antihypertensive Medication Regimen in Relation to Out-of-Pocket Costs, Adults Aged 35 to 64 Enrolled in an EmployerSponsored Health Insurance Plan, United States, 2014

\begin{tabular}{|c|c|c|c|c|}
\hline Variables & Unadjusted Odds Ratio (95\% Cl) & $P$ Value & Adjusted Odds Ratio ${ }^{b}(95 \% \mathrm{Cl})$ & $P$ Value \\
\hline West & $1.18(1.17-1.19)$ & $<.001$ & $1.16(1.15-1.17)$ & $<.001$ \\
\hline \multicolumn{5}{|c|}{ Geographic region } \\
\hline Rural & \multicolumn{4}{|r|}{1 [Reference] } \\
\hline Urban & $0.98(0.97-0.98)$ & $<.001$ & $0.99(0.98-1.00)$ & .002 \\
\hline
\end{tabular}

Abbreviations: $\mathrm{CD} / \mathrm{HD}$, consumer driven or high deductible health plan; $\mathrm{Cl}$, confidence interval; $\mathrm{HMO}$, health maintenance organization; PPO, preferred provider organization.

${ }^{a}$ Data are from IBM's MarketScan Commercial Database.

${ }^{\mathrm{b}}$ Adjusted for variables listed in the table.

${ }^{\mathrm{c}}$ This splits AHM users into 2 mutually exclusive groups: those who only filled prescriptions for generic AHMs in 2014 (88\%) and those who ever filled a prescription for a branded AHM in 2014 (12\%). 